\title{
The use of workbooks in South African grade 3 mathematics classrooms
}

\begin{abstract}
The poor performance of South African learners on national and international benchmark tests in mathematics and literacy has prompted the South African Department of Basic Education (DBE) to devise intervention strategies, one of which is the provision of workbooks for learners. This paper is based on a case study of six grade 3 teachers' use of DBE workbooks. Data from classroom observations and interviews are reported and analysed in relation to literature on mathematical and pedagogical resources. The key finding is that teachers use the workbooks in disparate ways as a resource and that the majority of the teachers in the case study use the workbooks in ways that do not resonate with the DBE's intentions. We argue that the provision of resources alone may not lead to improved teaching and learning in primary school mathematics classrooms and that pre-service and in-service teacher education programmes need to include a focus on how resources such as workbooks can be utilised optimally.
\end{abstract}

Keywords: workbooks mathematical resources, transparent resources, visible, invisible resource, primary mathematics, structured / unstructured resource

Corin Mathews, University of the Witwatersrand. Email: corin.mathews@wits.ac.za

Manono Mdluli, University of the Witwatersrand. Email: manono.mdluli@wits.ac.za

Valerie Ramsingh, University of the Witwatersrand.Email: valerie.ramsingh@wits.ac.za

South African Journal of Childhood Education | 2014 4(1): 80-94 | ISSN: $2223-7674$ |๔ UJ

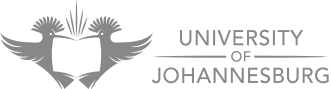




\section{Introduction}

A range of studies has shown that South African children lag behind their international counterparts in mathematics and language assessments (Shepherd 2011). In an attempt to address poor learner performance, the Department of Basic Education's (DBE) intervention strategy introduced in 2011 included the production and distribution of workbooks as additional support for teachers (DBE 2011b). These workbooks have been designed to support the teaching of mathematics and improve learner performance (Fleisch, Taylor, Herholdt \& Sapire 2011). Fleisch et al (2011) describes the workbooks as 128 carefully structured and sequenced mathematical worksheettype activities which teachers can use to enhance teaching and improve learning of mathematics. Each worksheet consists of a two page spread. The DBE suggests that a teacher uses four worksheet-type activities per week in an eight week term.

However, on closer inspection, it becomes clear that the extent to which the layout of the workbook helps to support teaching and learning is debatable. The logic behind the sequencing of the worksheets is difficult to follow. For example, worksheets 65-71 deal with place value and number patterns. Worksheet 68 , which deals with map work, is misplaced within the remaining worksheets which deal with number concept. We are of the view that children need more than one encounter with a topic such as map work to make sense of it and that one single exposure randomly placed does not make ideal conditions for conceptual development. Furthermore, the workbook does not have an index. This means that teachers need to search laboriously through the entire book each time they wish to locate a worksheet that addresses a particular concept and at the level at which they are teaching it. Additionally, the worksheets do not address all the concepts prescribed in the Curriculum Assessment Policy Statement (CAPS) (DBE 2011a). One example of this is Geometric Patterns, for which not a single worksheet has been designed.

The training manual accompanying the DBE workbooks suggests when to use work cards (which contain mathematical problems) and learners' exercise books and workbooks, in combination with other resources, some of which are already in classrooms - such as counters and flard cards (flard cards are used to show how numbers are formed /made up of hundreds, tens and units) - or those still to be made by the teacher (DBE 2012). The assumption underlying the use of workbooks is that

the prescribed lesson and exercise [will] ensure that teaching proceeds at the correct pace required to cover the curriculum and, most important[ly], that children [will] work from the text, reading and writing [and in the case of mathematics, calculating] everyday (Fleisch et al 2011).

Teachers need to understand the nature of mathematical and other resources and also how they can be used effectively to enhance learning. This paper presents stories of six teachers using the DBE workbooks followed by reflections on and discussion of findings emerging from these reflections. 


\section{Research design}

The research was a case study of the classroom practices of six grade 3 teachers; one from Limpopo Province and five from Gauteng. A case study can be defined as an on-site investigation that involves the study of a phenomenon within its real life environment using a variety of sources of information (Yin 2003). The data were collected from both classroom observations and interviews. The interviews were indepth, semi structured face-to-face interviews and were conducted individually with each of the six teachers who participated in the study. This methodology was chosen to enable researchers to gain a detailed understanding of how the six teachers use the DBE workbook. Of the six teachers who participated in the study, three are from Gauteng schools which are located within the province's Gauteng Province Literacy and Maths Strategy (GPLMS) project. This project was set up to offer support to teachers in low performing schools through the provision of detailed lesson plans. The lesson plans contain conceptual explanations, definitions and worked examples, which loosely resemble those in learners' books. The lesson plans also offer the teacher suggestions for chalkboard notation for each lesson (GDE 2012).

The data collection activities focused on how the six teachers used the DBE workbook as a resource in their mathematics lessons. The data collected and analysed aimed to respond to these two questions:

- What do teachers perceive the purpose of the DBE workbook to be?

- How do teachers use the DBE workbook?

The analysis of the classroom observations and of the interview transcripts provided insights into the use of a workbook as a resource in teaching and these are discussed in the final section of the paper.

\section{Workbooks as tools for the classroom}

While there is very little literature on the effectiveness of a workbook as a mathematical resource, Fleisch et al (2011) conducted a study in which the effectiveness of a workbook was compared to the effectiveness of a textbook. These authors concluded that there was no significant difference in learner performance between learners who used workbooks and those who used textbooks as resources. Thus, the provision of a resource such as a workbook or a textbook on its own does not guarantee an improvement in understanding of concepts and meaning making in mathematics. Uttal, Scudder and DeLoache (1997:45) argue that providing learners with mathematical resources in mathematics classes does not guarantee that they will understand concepts and make the necessary mathematical connections. While the provision of a workbook within the South African context may help to address some teaching and learning needs, we agree with the view that the provision of a resource like a workbook is not a guarantee that learner performance in mathematics will improve.

Lockheed and Verspoor (1991:57) argue that for any resource to be effective there has to be training on the use of that resource. Therefore, for teachers to optimally use 
the workbook, training on the use of the workbook and other resources is essential. The DBE Workbook Training Manual (DBE 2012) suggests that teachers use the workbook in relation to other resources, yet the training these teachers have received focuses predominantly on the exclusive use of the workbook.

While resources to teach mathematics play an important role in education, it is important to note that resources on their own may not lead to improved learner performance. The physical presence of a resource in a mathematics classroom does not on its own lead to learners discovering mathematical concepts and making meaning of the mathematics. Drews (2007:29) argues that for a resource to be effective there has to be a dialogue between the teacher and the learner while using the resource as a medium of explanation or demonstration, thus as a tool. This dialogue encourages thinking that could help to surface the mathematics that is embedded in the resource. Therefore, when choosing a resource, it is important for teachers to make some pedagogical decisions about why they choose a particular resource at a particular time and how they will use it to help learners to make sense of the mathematics. Bottle (2005:84) points out that when teachers select physical resources they should envision the extent to which the mental images that children form will be helpful in structuring their thinking.

The mathematics embodied in resources led Drews (2007:21) to classify mathematical resources as either structured or unstructured. Askew and Selinger (1998:13) describe structured resources such as cuisenaire rods, unifix cubes, Dienes blocks and abacus as "commercially produced objects specifically designed to embody a particular idea", while Drews (2007:25) sees unstructured resources as "everyday objects' such as counters, sticks and beads that can be used for counting and measuring". For some authors in the field of teacher education, resources are not limited to physical objects. They also include less tangible classroom pedagogic resources such as teachers' knowledge (Hoadley \& Jansen 2009), prescribed tasks and textbooks (Berger 2004), and online texts (Remillard 2005). While it has been argued that resources such as workbooks and textbooks play a critical role in assisting teachers to develop understanding of topics in the primary school (Harries \& Spooner 2000:46), Liebeck (1984:16) sees workbooks as offering "pictures and symbols rather than 'concrete' experiences and language". Constant exposure to pictures and symbols in the absence of relevant accompanying actions and language may create problems for learners. An over-reliance on workbooks may give learners the impression that mathematics is only located within workbooks and not in the real world (Drews 2007:24). This limitation in learner understanding could become silently malignant if the teacher does not employ other methods of teaching and assessing.

Atkinson (1992:13) further highlights the need for actions to be used alongside workbooks to facilitate learners' understanding of concepts. In other words, the relationship between workbooks and real life experiences needs to be mediated by the use of actions in combination with other mathematical resources, and by the use of language. The use of workbooks needs to be accompanied by actions which help learners make connections between words, pictures, and symbols so that they may 
make connections between the abstract and concrete (Haylock 2010:19). The view that resources on their own do not lead to learners making sense of the mathematics is supported by other researchers who argue that teachers' instructions when using resources are of vital importance (Uttal et al 1997).

Adler (2000:216) proposes that a mathematical resource should be transparent by being simultaneously both visible and invisible. The visible function of a resource includes the physical presence of a resource in the classroom which can aid meaning making. The invisibility function of a resource includes invisible aspects such as time (for example pacing, sequencing of activities and teacher time) and language (for example learners' verbalisation of tasks and teacher talk), which support the understanding of mathematics. A workbook as a resource needs to be visible in the classroom so that children can see and use it. In addition, this resource also needs to be invisible so that children can focus their attention on making meaning in mathematics. This notion of transparent resources challenges the way that many teachers use and understand workbooks as resources. Adler (2000:219) cautions that the introduction of a new resource can have both intended and unintended consequences. She asserts that a new resource in mathematics classrooms frequently become overly visible. It becomes the object of attention and the invisible functions of the resource become less of a focus in meaning making.

We return to the literature reviewed on workbooks and other resources for mathematics teaching in the final sections of the paper. In the next section we tell a classroom story about each teacher. In order to find a focus for each teacher's story the authors discussed and compared the data that emerged from the observations and compared this to the responses that teachers gave to each of the interview questions. A pseudonym has been given to each teacher.

\section{Stories of workbooks in the (mathematics) classroom}

\section{Teacher Samantha}

Teacher Samantha works in a rural school in Limpopo province. She uses Sepedi as the language of instruction while teaching her grade 3 class a mathematics lesson on counting in twos. Each learner has his or her own workbook, with text written in Sepedi, to work from. In one of the lessons observed, learners worked with two activities on pages 38 and 39 of workbook 1 .

For activity one there were four columns. In the first column 23 pairs of socks had been drawn. In the next three columns children were asked to answer the following questions: How many socks? How many pairs of socks? How many are left? Each question was placed on top of a column with an empty space underneath. The learners needed to provide an answer to these questions in this space.

In activity two, learners used the picture of socks provided to answer the questions in the columns. In task one there were 16 pairs of socks, with 1 extra single sock drawn, and learners were required to write down the answers to the three questions that were asked in the previous activity in the various columns. The subsequent task, as 
before, required learners to establish how many socks, how many pairs of socks and how many socks were left by counting the number of pictures of pairs of socks for the numbers 20, 37, 28 and 43. However, some children did not know what to do and could not complete the tasks as expected. In an attempt to aid their understanding the teacher instructed them to count the socks in ones. Even with teacher Samantha's help there were some children who could not cope. She moved from one learner to another to ensure that they were answering the questions correctly. In cases where learners were unable to give the correct answers, she would assist them by counting the number of socks in the picture in ones. Some learners struggled to answer correctly and to complete the tasks in the one hour lesson.

After this lesson was observed Samantha was interviewed. When she was asked what resources she used she stated "the resource that I used was the workbook from the department". When asked what the purpose of the workbook was she replied "something which you use during the lesson to show the learner", and when asked to describe how she used the resource in the lesson described above she stated "first I wanted them to count in two's [as well as] write, [then develop their] hand and eye coordination [and] pointing when counting".

In the lesson described, the workbook was central to both the teacher and the learners. Importantly, both the teacher and learner had access to a mathematical workbook that was in their mother tongue. Throughout the lesson the teacher did not supplement the workbook with any other resources. She asked the learners only the questions that appeared in the workbook. Learners were then called upon to write the answers in the workbook. It was apparent that some learners provided incorrect written answers to the questions. In those cases, the teacher would verbally suggest an answer after discussion, and learners would then correct the answer. In her interview teacher Samantha affirmed that the workbook was something that was used throughout the lesson. Although she alluded to the presence and the value of using other resources none were evident in her classroom. Interestingly, teacher Samantha indicated that what was important to her was that the learners counted in twos, yet when they provided incorrect answers she counted in ones. There was no evidence in either the lesson or the interview that she was aware of the importance of teaching learners how to count in twos, or that she knew how to do this effectively.

\section{Teacher Mary}

Teacher Mary is a teacher who was not trained as a foundation phase (grades 1 to 3 ) teacher, but who has been teaching FP classes for 20 years. She is currently the head of the phase in a previously disadvantaged school, which is now a GPLMS school. She used the English DBE workbook. During one of the observed lessons her focus was on the understanding of place value and expanded notation in the number range from 500 to 600 . At the beginning of the lesson she used the chalkboard to explain the concepts of place value and expanded notation. This was done so the learners would be able to complete the tasks in the workbook. While teaching, the teacher stated that "different groups will be given different questions". However, the teacher 
gave the same activities to all the learners in the classroom. In her explanation at the chalkboard the teacher connected her lesson to previous lessons that she had taught. She supported the teaching of the lesson with the use of flard cards, base ten blocks, number chart and work mats which she had made and which enabled learners to count out numbers. After the teacher had taught the new concept, learners worked in their workbooks.

Throughout the rest of the lesson the learners worked independently and the teacher moved around to assess whether learners were struggling. In some cases, where this was so, she would discuss a solution with them. In other cases learners would come up to her and she would provide solutions to their concerns. From the interview with the teacher the following became evident. Teacher Mary based her lesson on the requirements of the lesson plans that were provided by the district office of the provincial education department. She then indicated that she would supplement the activities in the workbook with activities that did not come from the department of education. The teacher said, "over and above teaching the lesson plans, I incorporate my own [worksheets] if I see that the kids are unable to manage with what has been done in the lesson plans". She then mentioned that the workbook is used "to reinforce what was taught for the day". She had noticed that the same concept was found on different pages in the workbook and stated that a teacher needed to make selections because "the concept, place value might be on page 2 at the beginning of the workbook and again on page 10 of the workbook". Teacher Mary used the workbook to reinforce the concept for the day: "I don't just give them the book and say, 'right start', because you have to reinforce with something that the children have been exposed to for the day".

Teacher Mary was also clear that she viewed "the DBE book as a resource" to be used in conjunction with other resources. According to her, she used the workbook "everyday" and went beyond what the guidelines require: "I don't just stick to the pages they require". Another function of the workbook for this teacher was to "use it a lot for the ANA (Annual National Assessment) preparation". Teacher Mary also mentioned that she used the workbook to identify learners' errors as she marked their workbooks. According to her the workbook needed to be mediated in that "you do not just say like any other resource or any textbook, it's not the kind of thing that you give a child and say, 'ok start". She also stated that the workbook was "structured" and aligned well with the "CAPS document" and therefore covered "those concepts that you're supposed to cover within the term". For teacher Mary the workbook should be used as a guideline. In her view, teachers must themselves select the most appropriate activities. She stated. "I make my own selections". Importantly, while referring to the workbook she mentioned "it is not a crutch".

While the workbook is central to teaching and learning in teacher Mary's classroom and is used every day, it is used in conjunction with other resources in order to reinforce concepts. 


\section{Teacher Boni}

Teacher Boni is an experienced foundation phase teacher within a GPLMS school who used the English version of DBE workbook 2 in her class. At the beginning of the first lesson observed, she asked children to turn to page 2 of the workbook. There was no evidence of a lesson plan or any reference to a lesson plan in this lesson and the subsequent lessons. Teacher Boni asked learners to count numbers on the grid on page 2 from 500 to 600 . Learners struggled with this initial activity. In the second lesson learners confused numbers 506 and 560 as they stated the number names. Their teacher brought in a different number sheet, which was not from the DBE workbook, with numbers 400 to 405 . She asked learners to say the number names of the numerals on this sheet. This activity was aimed at helping learners to understand the difference between 506 and 560 . After reading out these numbers, the teacher drew a grid with numbers from 500 to 600 on the board, and counted in ones. Subsequently, she circled numbers 506 and 560. She then asked the learners which number came first. Learners responded that 506 came before 560. She then asked learners to do the activity at the bottom of page 3 , which required learners to order numbers from the biggest to the smallest. In the second set of numbers there were numbers 506 and 560 and again learners displayed confusion in terms of ordering these numbers. In the third lesson, teacher Boni did not make use of the workbook. She used activities that she had designed to reinforce mental mathematics activities. The activities required learners to break down numbers like 12, 17, 107 and 511. Thereafter, they needed to identify the value of the underlined digits in $7 \underline{2} 1,346,42 z, 8 \underline{0} 7$ and $\underline{8} 90$. Teacher Boni asked questions about the value of the underlined numbers and learners responded to her questions. In a situation where a learner gave an incorrect answer, she repeated the question and asked a different learner for the answer.

During the interview, teacher Boni was asked how she planned her lesson and how she incorporated the workbook into her planning. She responded by saying "I use the workbook to take out some activities and incorporate these activities in my lessons so that children can see that I get these activities from the workbook". When asked about the resources she used she said "I use the DBE workbook as a resource" and when asked about her reasons for choosing to use the workbook she said "I use the workbook for integration and reinforcement purposes". When asked when she uses the workbook, she said "I only bring in the workbook after I have taught a concept".

From the classroom observations of this teacher's lessons it was evident that the workbook was used throughout the lessons in conjunction with additional worksheets which were not from the DBE workbook. However, the additional number sheet did not use the same number range as the number range the teacher worked with from the DBE workbook. As a result the workbook and the additional worksheet did not help learners to understand which of 506 and 560 is the bigger number. The exchanges in teacher Boni's lessons were mostly characterised by teacher questions and learner responses. Throughout the lessons, the teacher made no reference to the GPLMS lesson plan or her own lesson plans, though she indicated in the interview that she incorporates activities from the workbook into her own lessons. While teacher 
Boni stated that the workbook is a resource which she uses only after she has taught a concept in order to integrate and reinforce the concepts taught, in practice she used the workbook as more than just a supporting resource. Thus there were significant differences between her espoused and enacted practices.

\section{Teacher Violet}

Teacher Violet is qualified as a senior primary teacher and is located within a GPLMS school. She has been teaching foundation phase for 4 years. She used the English version of DBE workbook 2 in her class. Though this teacher was observed for the first time on the same day as teacher 3, she started her first lesson by asking learners to open to page 7 of the workbook which dealt with counting from 601 to 700 as she walked to the chalkboard. As learners were counting, teacher Violet observed that some learners were not identifying the correct number names. Where learners were struggling, she drew the grid with numbers from 601 to 700 on the board and pointed to the numbers as learners counted aloud. In situations where learners made mistakes, the teacher corrected them by saying the correct number.

Teacher Violet then moved to the second activity within the workbook that focused on place value and requested the learners to count the 100s, $10 \mathrm{~s}$ and $1 \mathrm{~s}$. Subsequently, learners were asked to look at the three number lines in the workbook and were expected to fill in the blank spaces for numbers in the range 600 to 700 . Learners were later asked to order numbers from the smallest to the biggest. Similar to teacher Boni's class, learners struggled to see the difference between 650 and 605 . When learners provided incorrect answers, the teacher copied the activity directly from the workbook onto the board and provided the answers. On the second day the teacher moved on to the activity with the number range from 600 to 700 using pictures of Dienes blocks. Learners needed to look at the picture of blocks and to write the addition number sentence. In a situation where learners could not provide the correct answer, she provided the answer or asked another learner to do so. On the third day she skipped pages 8 and 9 of the workbook and focused on the next activity on pages 10 and 11, which involved the use of a number line on which learners were expected to fill in the blank spaces. Some learners could not do the activity successfully. She then drew a number line as represented in the workbook on the board and together with the learners filled in the blank spaces.

In the interview, teacher Violet was asked to describe the resources she used in her teaching. She responded "I did not use any resources but only a workbook". Subsequently, she was asked how she used the workbook and responded "I used it to develop counting from 500 to 600 and from 600 to 700 ". When teacher Violet was asked why she chose to use the workbook she indicated "I used the workbook because we were told to use it". She was subsequently asked why she skipped pages 9 and 10 of the workbook. She responded "because these pages are based on map work and I do not know how to teach map work". In addition the teacher was asked how she incorporated the workbook into her lesson plans. She responded "I do not have any lesson plans as I am waiting for a new set of lesson plans from GPLMS". 
In all the lessons observed, teacher Violet copied activities directly from the workbook onto the chalkboard and made no reference to a lesson plan. The workbook served as the basis for her teaching as there was no evidence of lesson plans. There was no evidence of the use of any other resource other than the workbook and the chalkboard. What is concerning about this story is that teacher Violet does not consider a workbook to be a resource for her teaching, does not understand some of the content in the workbook, and thus chooses to omit it, and has chosen to wait for lesson plans to be provided rather than devising her own.

\section{Teacher Sinah and teacher Mpho}

In this school, the two teachers who were observed planned together and used a very similar approach in their teaching. For this reason their practices are described together in one story.

Both teachers are experienced teachers who teach in the medium of English. In the lessons observed both teachers and all of the learners had access to English workbooks. Both teachers began their lessons by asking the learners to take out their DBE workbooks so that they could check their homework from the previous day. In the lessons observed, the learners worked sequentially through the workbook completing worksheets 65,66 and 67 in succession. Concepts covered in the three worksheets were counting in ones (500 to 600 and 600 to 700 ), place value concepts in the same number ranges (sequencing numbers, placing numbers on a number line and expanded notation) and number patterns (in the $1 \mathrm{~s}, 2 \mathrm{~s}$ and $5 \mathrm{~s}$ patterns).

Almost every learner had completed their homework. Learners marked their own books. Those who had not done or brought their homework were allowed to look in their partner's books while they marked their homework. The teachers went through each task in the workbook with the whole class. For the counting in ones tasks the learners counted from the grids that they had completed. For marking the remaining questions, one learner was invited to copy answers from his /her worksheet onto the chalkboard. The rest of the class ticked off their answers based on what the learner had written on the board. When learners' responses were incorrect, they inserted the correct answer above the incorrect answer in their workbooks. In using this approach no resources other than the DBE workbook and the chalkboard were used. Most learners got all their answers right. This part of the lesson took about 40 minutes. Immediately after marking the homework the teachers asked the learners to write in their diaries that they would need to do the next two pages for homework.

Thereafter the learners spent about 10 minutes on their Mental Maths tasks which were sourced from SA Teacher documents provided by the district office. On each of the days the teachers wrote the answers to the Mental Maths questions on the board before the learners arrived in the morning. First the learners swopped books for marking the Mental Maths work that had been done in class on the previous day. After marking the Mental Maths tasks the learners copied and completed the ten questions to be done as part of the maths lesson. Once the Mental Maths had been done teachers began teaching the lesson they had planned. 
The concept taught was based on the schedule provided by the district office in a document called the Plotting grid. The Plotting grid suggests sequence and pacing of teaching in the maths curriculum. In each lesson observed, during this part of the lesson, both teachers worked on the concepts of number patterns and geometric patterns and used concrete shapes and activity cards to assist them. At the same time they set independent tasks for the different ability groups.

The lesson observations were followed by interviews with each teacher. From the interviews the following became evident. The teachers do not see the DBE workbook activities as being part of the mathematics lesson. In discussion, when describing the sequence of their activities they said that they begin with the DBE worksheet activities and once these have been checked they proceed to teaching their maths lessons. The teachers agreed that since the Plotting grid was designed by the district office to "guide [them] on which concepts to cover on a weekly basis" it was the main driver for selection and pacing of teaching. Additionally, they were required to do some Mental Maths and use the DBE workbook. Because these requirements overloaded the maths lesson, the school had decided to use the workbooks for homework. This new approach was a departure from the approach the school had followed previously where teachers developed and set homework which would reinforce the work that was taught in the class.

When assigning the homework teachers Sinah and Mpho would say to the class "go and do these pages" without checking whether the pages related to what had been covered in class or not. In the interview, teachers Sinah and Mpho said "Learners are expected to read the instructions for themselves and do the work on their own, without the teacher explaining and doing everything for them. [This is our way of] training them for the ANA".

When asked about how the learners coped in interpreting the tasks set both teachers agreed that "their parents have to assist them". Teacher Sinah revealed that her "good ones [sic] do their homework but the weaker ones [often] tell you that their parents were not there or are busy [and could not help them]". Teacher Mpho admitted that some children reported that parents complained that "your teacher is giving me problems, there's a lot of work, I can't help you" and that some parents did the homework for their children. She explained that she "realised that [the parent] was writing the homework [because] it wasn't in their [the child's] handwriting". Teacher Sinah reported similarly.

From the observations and interviews it became evident that the workbooks were used exclusively for homework on a daily basis. The homework or workbook activities were treated as an aside and not part of the main maths lesson for which teachers Sinah and Mpho prepared thoroughly. The workbook activities were not mediated. Parents were required to mediate the homework and in some cases they even completed the tasks for their children. With these teachers believing that they needed to simultaneously use the multitude of disparate district and government documents offering support on how to negotiate the mathematics curriculum, their approach was uncoordinated. 


\section{Discussion}

The discussion is divided into three parts. Firstly, we discuss what the teachers in our study perceived the purpose of the DBE workbook to be. Secondly, we consider how these teachers used the DBE workbook, and finally we suggest some implications of our findings for pre-service and in-service teacher education programmes.

\section{Teachers' perceptions of the purpose of the workbook}

Findings from our analysis of both the classroom observations and the interviews indicate that the teachers in this study used the workbook for different purposes. These include reinforcement, integration, homework, compliance with the demands of the education department and ANA preparation. According to Fleisch et al (2011) the DBE workbook was designed to assist with coverage of content. Most of the teachers appeared to have covered the content required by the official documents at a particular time in the school year but they used the workbook in very different ways.

\section{How teachers used the workbook}

Atkinson (1992) states that additional resources should be used to complement workbooks and that these are critical for developing mathematical meaning and understanding. Four of the teachers used the workbooks in isolation from other mathematical resources, while one of the two teachers who used an additional resource used it inappropriately because the number range in the workbook did not match the number range in the additional number sheet. Only one teacher selected additional resources which matched the concept and activities in the workbook task. These additional resources were flard cards, base ten blocks, number charts and working mats. Some of the teachers seemed to think that the use of the workbooks alone was sufficient for the development of mathematical meaning and understanding. However, Drews (2007) argues that if learners only use books to solve mathematical tasks these learners develop the idea that mathematics only exists in a book. Workbooks, like other books, offer pictures and symbols only to the exclusion of concrete experiences and extended discussions which are crucial in mathematics teaching and learning. Furthermore, when other resources are absent a lack of actions prevents learners from making connections between symbols, pictures and words (Haylock 2010).

Adler (2000) suggests that resources should be used as transparent resources (both visible and invisible) so that learners can make sense of their mathematics. Yet, in several of the classrooms it can be argued that the use of the resource became too visible as the workbook became the most important object of attention rather than the mathematics itself (Adler 2000). In other words, in these classrooms workbooks are used by learners in class, or for homework activities, but their mathematical understanding is not developed. Only in one teacher's classroom (teacher Mary) does both the invisible and visible use of a resource become evident. The teacher ensured that she used the workbook "everyday" to teach. This is the visibility function. The resource was available for her and the learners to touch, see and use. She also used 
this resource in conjunction with other resources to support the teaching of concepts. She selected and sequenced activities from the workbook according to topics and concepts she wanted to develop. This is the invisibility function which goes beyond having and using the resource "everyday". In teacher Mary's class, the workbook became a transparent resource with a dual function in the sense that it was used every day (visible function) and was also used to develop mathematical understanding which requires pacing and coverage of the curriculum. Thus, most of the teachers in this study used the workbook as a provider of activities for the classroom (a visibility function) without selecting, pacing and sequencing activities accordingly to support development of various mathematics concepts (an aspect of the invisibility function). Another way teachers used the workbook was to select worksheets to use for covering a particular topic. One teacher worked with page 7 of the workbook and decided to skip pages 8 and 9, because these pages focused on map work which she said she did not understand. She moved to pages 10 and 11 which followed on from page 7 in continuing to deal with numbers. Her decision raises some questions about the ways in which concepts are grouped in the workbook and about her own mathematical knowledge. We argue that for a workbook to be optimally used, it has to be pedagogically sound. As it is, the DBE workbook is designed with various activities on the same concept located in different parts of this resource. Fleisch (2011) has pointed out that classroom teachers are faced with many challenges, which include challenges relating to curriculum coverage, pacing and sequencing. Based on our understanding of the challenges teachers face, we argue that teachers need a workbook that is characterised by activities that are carefully selected, sequenced and differentiated to assist them to deal with challenges of curriculum coverage, sequencing and pacing.

Five of the teachers used the workbook in isolation from any activities or resources with teacher - learner dialogue restricted to teachers asking closed questions, learners providing answers and filling in answers in the blank spaces in the workbook. Drews (2007) argues that for a resource to be effective its use has to be accompanied by mental activity which includes dialogue between the teacher and learners, and Haylock (2010) further suggests that there has to be a connection between talk, concrete items and actions in order to bridge the gap between the resource and the mathematics embedded in the resource.

In some of the lessons observed, the workbook was used for homework purposes. Learners were directed to pages in the workbook to go and work on at home. The responsibility of teaching the content in the workbook shifted to parents or other caregivers. As pointed out in the stories of teachers Sinah and Mpho, some learners managed to do the work and others got parents to do the work for them. This practice of using a workbook for home work poses a challenge for parents, because they are not trained to mediate the mathematical knowledge within the resource. As noted by Lockheed and Verspoor (1991), for a resource to be effectively used training on its use is vital.

Classroom observations indicate that in some classes where a workbook was used for homework there was no relationship between the homework (DBE workbook 
activity) and the maths lesson that was taught. Teachers in these classrooms explained that the school's approach was that workbook tasks did not need to be mediated because at the grade 3 level learners need to work independently. This unmediated use of the workbook is contrary to the intention of the DBE (2011b).

\section{Conclusion: A need to define a clear purpose for the workbook}

When the purpose of a resource (in this case the workbook) is not clear, teachers struggle to use it to assist learners to develop mathematical concepts and understanding. Furthermore, the lack of clear purpose results in teachers using the workbook for a multitude of reasons other than those intended by the designers.

\section{Use of the workbook in conjunction with other available mathematical resources}

Any resource in the mathematics class should be used in conjunction with other resources in order to optimally develop mathematical concepts. Resources used in isolation from other mathematical resources do not enable learners to develop a connection between ideas. Teachers need to strive to make resources transparent in the classroom, so that the workbook, although a new resource in the classroom, fades into the background and so that mathematical meaning and concept may become central for both teaching and learning.

\section{Implications for pre-service and in-service teacher development programmes}

The findings of this paper raise important issues for in-service and pre-service mathematics teacher educators. Teacher education needs to take cognisance of the generally low levels of mathematical conceptual understanding of foundation phase teachers in this country (Fleisch 2011) and make a more concerted effort to raise these levels.

While the efforts of the DBE to produce workbooks to ensure curriculum coverage should be applauded, the efficacy of this intervention needs further thought. Access to resources is not enough. Teachers need to be know how to use resources, how to exploit the affordances of each resource they have and when and how to use them, either alone or in concert, in order to promote optimal mathematical understanding in their learners.

We also suggest that when a new resource is distributed to serving teachers, such distribution should be accompanied by workshops for all the teachers. In these workshops teachers should have opportunities to work with the resource in conjunction with other relevant resources and to learn from both the workshop facilitator and one another.

\section{References}

Adler, J. 2000. Conceptualising resources as a theme for teacher education. Journal of Mathematics Teacher Education, 3(3):205-224. 
Askew, M. \& Selinger, M. 1998. Teaching primary mathematics. London: Hodder and Stoughton.

Atkinson, S. 1992. Mathematics with reason: The emergent approach to primary maths. London: Hodder and Stoughton.

Berger, M. 2004. The functional use of a mathematical sign. Educational Studies in Mathematics, 55:81-102.

Bottle, G. 2005. Teaching mathematics in the primary school. London: Continuum.

Department of Basic Education (DBE). 2011a. Curriculum and Assessment Policy Statement (CAPS): foundation phase mathematics grade $R-3$. Pretoria.

DBE. 2011b. The Rainbow Workbooks. Retrieved from http://www.ar-t.co.za/DOEFlyer/ Workbooks\%20flyer\%201706.pdf (accessed 25 July 2011).

DBE. 2012. Workbook Training Manual. Retrieved from http://www.education.gov.za/ LinkClick.aspx? fileticket=VK3rUc\%2BmgmM\%3D\&tabid=643\&mid=2413/Default. aspx (accessed on 14 July 2014).

Drews, D. 2007. Do resources matter in primary mathematics teaching and learning? In Drews, D. \& Hansen, A. (eds.). Using resources to support mathematical thinking, primary and early years, pp. 19-31. London: Learning Matters Ltd.

Fleisch, B., Taylor, N., Herholdt, R. \& Sapire, I. 2011. Evaluation of back to basics mathematics workbooks: A randomised control trial of the primary mathematics research project. South African Journal of Education, 31(4):488-504.

Gauteng Department of Education. 2012. GPLMS coaches manual. Johannesburg: GDE.

Harries, T. \& Spooner, M. 2000. Mental mathematics for the numeracy hour. London: David Fulton.

Haylock, D. 2010. Mathematics explained for primary teachers. London: Sage Publications.

Hoadley, U. \& Jansen, J.D. 2009. Curriculum: Organizing knowledge for the classroom. Oxford University Press Southern Africa.

Liebeck, P. 1984. How children learn mathematics: A guide for parents and teachers. London: Penguin.

Lockheed, M.E. \& Verspoor, A.M. 1991. Improving primary education in developing countries. Oxford: Oxford University Press.

Remillard, T. 2005. Examining key concepts in research. Review of Education Research, 75(2):211-246.

Shepherd, D.L. 2011. Constraints to school effectiveness: What prevents poor schools from delivering results? Department of Economics Working Papers 5/2011. Stellenbosch: Stellenbosch University.

Uttal, D.H., Scudder, K.V. \& DeLoache, J.S. 1997. Manipulatives as symbols: A new perspective on the use of concrete objects to teach mathematics. Journal of Applied Developmental Psychology, 18(1):37-54.

Yin, R. 2003. Case study research: Design and methods. (3 $3^{\text {rd }}$ edition). Thousand Oaks, CA: Sage. 